\title{
First approach to the modeling process of the sensor base on fiber optic for the detection of vehicular overload.
}

\author{
Hernán Paz Penagos, Ph.D ${ }^{1}$, Sandra X. Campagnoli, Geotechnical specialist ${ }^{2}$, Leidy J. González ${ }^{3}$, Juan F. Martin ${ }^{4}$ and \\ Juan C. Gómez ${ }^{5}$, Engineering students ${ }^{3-5}$ \\ ${ }^{1-5}$ Escuela colombiana de Ingeniería JULIO GARAVITO, Colombia, hernan.paz@escuelaing.edu.co, \\ sandra.campagnoli@escuelaing.edu.co, leidy.gonzalez-c@mail.escuelaing.edu.co, juan.martin@mail.escuelaing.edu.co, juan.gomez- \\ ru@mail.escuelaing.edu.co
}

Resumen-En este artículo se explican los avances logrados en el proceso de modelamiento teórico del sensor basado en fibra para detección de sobrecarga vehicular. El diseño metodológico cubre la primera fase de revisión del estado de arte, y la segunda, de experimentación de laboratorio y simulación para obtener una primera aproximación al modelo del sensor. La investigación se hará para cargas estáticas correspondientes a vehículos $\mathrm{C} 2$ de peso vehicular bruto máximo de 17 Toneladas, distribuido en el eje simple direccional y en un eje simple no direccional. Como resultados parciales se presentan la selección del tipo de señal y sus parámetros más adecuados; así, como el comportamiento de la fibra óptica frente a esfuerzos.

Palabras claves - Fibra óptica, modelo teórico, pavimento asfáltico, propagación, sensor, sobrecarga.

Abstract - In this article we explain the progress made in the theoretical modeling process of the fiber-based sensor of the detection of vehicular overload. The methodological design covers the first phase of revision of the state of art, and the second, of experimentation of laboratory and simulation to obtain a first approach to the model of the sensor. The investigation will be carried out for static loads corresponding to vehicles C2 of maximum vehicular weight of 17 Tons, distributed on the simple directional axis and on a simple nondirectional axis. The selection of the type of signal and its most suitable parameters are presented as partial results; so, like the behavior of the fiber optic against efforts.

Keywords- Fiber optic, Theoretical model, Asphalt pavement, Propagation, Sensor, Overload.

\section{INTRODUCTION (HEADING 1)}

The high costs in the implementation, maintenance and installation of the sensors for weigh-in traffic in Colombia limit road agencie's control of overload in the secondary and tertiary routes; for that reason, it is necessary to investigate new technologies in order to design more economic sensors.

The present investigation refers to the topic of sensors based on fiber optics for the detection of vehicular overload. Through this research it is pretended to reach a theoretical model represented by one equation based on experiments, simulations, analysis of data and regression.

Digital Object Identifier (DOI): http://dx.doi.org/10.18687/LACCEI2018.1.1.208 ISBN: 978-0-9993443-1-6

ISSN: $2414-6390$

\section{THEORETICAL FRAMEWORK}

\section{A. Problematic}

Most of the damage in the structures of pavement are generated due to the weight of the vehicle's that transit on it. Even if in Colombia, the dimensions and loads of vehicles of the land transport, are regulated by the Department of Transport, according to the resolutions 4100 of December 28thr, year 2004, 2888 year 2005, 6427 year 2009 and 1782 year 2009 [10], [11], [13], the operation conditions of many vehicles that transit national and urban roads, in special roads that don't have concessions, deviate from the required standards.

B. Selection of the typical vehicle for the study

The type of vehicle that transits with most frequency in the roads of Colombia and the city of Bogotá, corresponds to $\mathrm{C} 2$. This vehicle is a two axe Truck, with a maximum permissible gross weight of 17 tons, distributed in a simple directional axis of 6 tons and one simple not directional axis or simple axis of double wheel of 11 tons. Therefore, this vehicle was chosen due to the fact that it represents the most impact on the Colombian road infrastructure.

\section{Load-weighing intelligent devices}

In order to determine the traffic loads that circulate along the pavement, scales that can be fixed or mobile, statics or dynamics are used. In recent years, WIM (Weigh In Motion) scales have begun to be used in the country. Some sensors used to weigh vehicles in movement are: panels of reflection, piezoelectric sensor, sensor of capacitance and fiber optic sensor [16], which utilizing piezoelectric, photoelectric and capacitive principles.

\section{The fiber optic}

The fiber optic is a medium of transmission guided that is configurate with the cylindrical geometry. In the center have a nucleus with radius $a$, constituted fundamentally with fiberglass, that have one index of refraction bigger than that of the covering (surrounding environment to the core). This is an external cylinder of polyethylene, with radius $b$. The fiber's optics according to the number of propagation modes (paths of

$16^{\text {th }}$ LACCEI International Multi-Conference for Engineering, Education, and Technology: "Innovation in Education and Inclusion”, 19-21 July 2018, Lima, Peru. 
light through to the fiber optic) are classified in singletransverse mode and multimode.

\section{E. Interferometry and reflectometry}

Are two properties of the light that are very important in the detection process of physical variables of the sensors based on fiber optic. The interferometry or interference of light is a physic principle that consist in the linear overlay of two or more waves in a given point, that create a particular and variable pattern (formation of strips with zones of high, few or no wave activity).

The reflectometry in a medium of transmission is the second property of the light, which measures the reflection coefficient (relation between the level of the homing signal and the incident wave), the time it takes for a propagation signal to going and return in the same point of emission, the propagation velocity and the track distance (Romero, 2012).

\section{F. Sensors based on fiber optic}

The sensor is a device that detect a change in a physical stimulus and transform it in a signal that can be registered and measure. The basics components of the sensors are: sensor element, transducer and an electronic system. Actually, owing to research and the rise of the optic components, have been explored the design and the construction of the sensors based on fiber optic. The optic sensors compared with the sensors based on electrical principles are more immune to electromagnetic interferences and the radiofrequency, have low-loss, small sizes, high sensitivity and reliability to long term. Below, presents a type of optic sensors.

The type of sensors quasi-distributed or fiber Bragg grating (FBG) is a structure that have a millimetric length, and can photo-register in the nucleus of a fiber of telecommunications single-transverse mode standard. As shown in the figure 1, acts as a selected mirror in function of the wavelength. It's means that, if injected in the fiber optic the light emanating from a source of broadband, the network only reflects light with a spectral width, very narrow, centered around to wavelength of the fiber Bragg grating. The rest of the light is transmitted by the fiber optic without any loss, until the next FBG impress in the fiber.
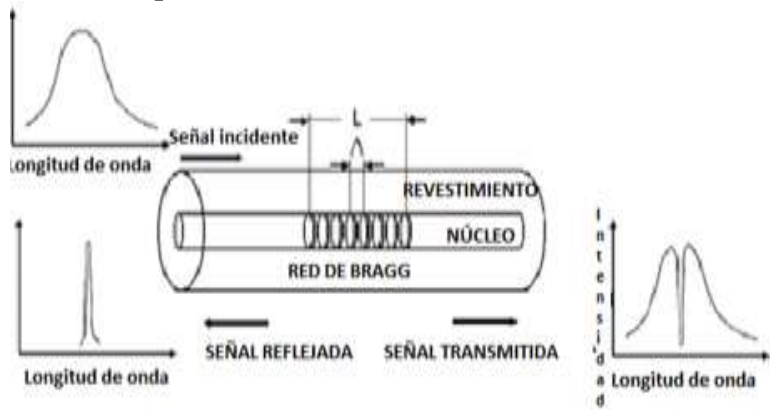

Fig. 1. Fiber Bragg grating.

A Fiber Bragg grating have unique characteristics that allow to use it like sensor. For example, if the fiber is retired or compressed, the network can measure the deformation. The deformation of the fiber optic produces a change in the period of the microstructure and, for consequently, also in the wavelength of Bragg. The wavelength of the FBG $\left(\lambda_{B}\right)$ is expressed in terms of the period of the microstructure $(\Lambda)$ and refractive index of the nucleus $\left(\mathrm{n}_{\mathrm{ef}}\right)$.

\section{SELECTION OF THE TOOL OF WORK}

The objective of the first experiences in the laboratory, under controlled conditions, was to transmit analog and digital waves, baseband and modulated over a kit of fiber optic DL 2570 . With the above, sought to identify the signal to present minor attenuation, time lag and variation of frequency, to select it as a sign of reference. Also, was stimulated the behavior of the fiber optic regarding to deformation and efforts occasioned for overload, for evaluated the strength of the material.

\section{A. Specifications of the equipment of experimentation}

The panel DL 2570 of fiber optic is built for transmitters and recipients analogical and digital respectively. The analogical modules and the digital connect with one singletransverse mode with length of fiber of $50 \mathrm{~cm}$ y $5 \mathrm{~m}$. This fiber is composed by one core of plastic fiber ULV-0: ABS_PC with high resistance to the impacts and to the heat (with diameter of $1 \mathrm{~mm}$ ), and the coating of polyethylene PE (with diameter of $2.2 \mathrm{~mm}$ ). The source of light is a diode LED to $660 \mathrm{~nm}$. The receiver adapted with a diode PIN with amplification of low-mismatch integrated. Across to the panel the electromagnetic waves (light) are transmitted in the first window of transmission: $950 \mathrm{~nm}$. The attenuation of the fiber optic de $2.3(\mathrm{Db} / \mathrm{Km})$. In the panel, any analog or digital extern signal with amplitude between 0 and $650 \mathrm{mVpp}$ can be ingress; the range of frequency must be between 0 to $20 \mathrm{MHz}$. The panel of fiber optic DL 2570 can work in the range of temperature between $0-70^{\circ} \mathrm{C}$.

\section{B. Transmissions tests of modulated tones and signals}

Initially there were realized tests of transmission of signals across the kit. With the use of oscilloscopes, generators and sources, tones were conditioned to different frequencies and extents to transmit them and to visualize them at the recipient's end. Also, one affected the conduit with folds, tensions and weight; across these, one was seeking to identify variations in the amplitude, bandwidth and lack of coordination of the sign band bases transmitted.

Subsequently were transmitted modulate signal analogically (in amplitude, frequency and phase) and digitally (FSK). In the experimentation with modulate signals were used two function generators: one of them for extract the modulate signal -represent the message- and the other for generate the carrier function. The second generator also was used for making the product of the two mentioned signals: analogue modulation AM, FM, PM and digital: FSK. The output of the last generator was connected to the panel DL 2570 and the

$1^{\text {th }}$ LACCEI International Multi-Conference for Engineering, Education, and Technology: "Innovation in Education and Inclusion”, 19-21 July 2018, Lima, Peru. 
modulate signal was connected through the kit for the two lengths of the fiber optic $(50 \mathrm{~cm}$ and $5 \mathrm{~m})$, as shown in the figure 2 .

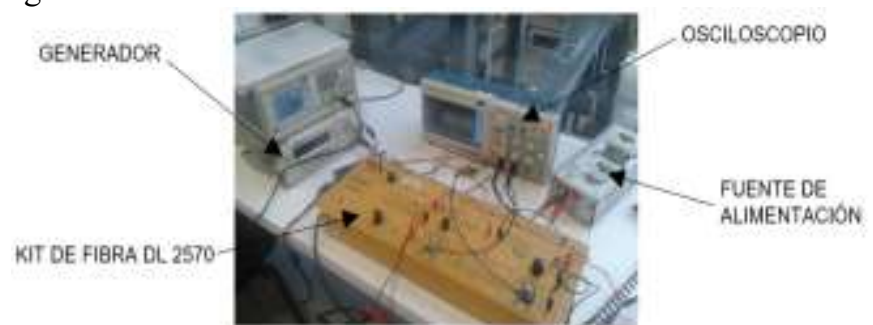

Fig 2. Transmission test of the light through the kit of fiber optic DL 2570 with the use of oscilloscope, generators and sources.

The objective with the transmission of signals baseband and modulate (passband) through of the two lengths of fiber optic $(50 \mathrm{~cm}$ y $5 \mathrm{~m})$, was compared the signals send out and the signals received to evaluated attenuation, time lag, and the variation of the frequency (bandwidth) in the transmission medium.

\section{Load-weighing intelligent devices}

Other investigative activity done in groups, that implicated the characteristics of the fiber (panel DL 2570), was similar in the intrinsic behavior of the fiber optic in the environments with presence of charges (subject to deformation) and environmental variable conditions. In order to this purpose was used the software SolidWorks ${ }^{\circledR}$ (2017).

With the simulation is claimed to assess the response of the fiber wire in order to one charge distributed of $29.43 \mathrm{kN}$ (3 tons) in a unique direction parallel of your transverse axis. The maximum force specified shall be pursued for a pneumatic of the semi-axis of the wheel simple of a truck C2 over the land. It is assumed that the pneumatic have a pressure of 100 psi and leaves a vehicular print over the pavement for that reason could tell the application area of the forces.

In the order to evited that the fiber have expose to adverse conditions over the pavement, is coated with a material that prevents the wear for the damp and gradients of temperature, that ensure most useful life.

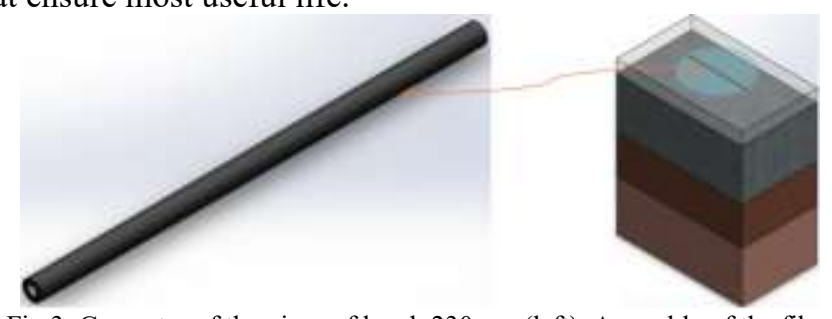

Fig 3. Geometry of the piece of lengh $230 \mathrm{~mm}$ (left). Assembly of the fiber cover with the plate of poliethylene leaning against the asphalt layer (right)

With the advanced activities during the first two phases of investigation is expected obtain sufficient evidence in order to initialize the modeling process to the sensor.

\section{RESULTS}

As shown in the table 1, to transmit analogically a tone (signal baseband) throught to the panel DL 2570, with lengths of fiber optic of $5 \mathrm{~m}$ and $50 \mathrm{~cm}$, is evidenced in the signal received an exact duplicate of the transmitted signal. In consequently, attenuation isn't experimented, time lag and variation of the frequency. However, when was transmitted the same tone thought the same panel, but in this case the transmission medium suffers creases, the signal received is mitigated 2.66 times the transmitted signal, not suffers time lag, an any variation of the frequency.

In the first column of the left is specified the signal types with the parameters that intervened in the modulation process both analogic and digital; in the next columns, the graph in the time domain and the frequency of the signals recovered in the receiver. In the last graphs on the time domain is evident the average power reduction in the modulate signals AM, FM, PM and FSK when were propagated throught of the fiber optic with the lengths of $5 \mathrm{~m}$. About to changes of frequency, the schematics FM and PM change for the lengths of $50 \mathrm{~cm}$ and $5 \mathrm{~m}$. 
TABLE 1

SIGNS OF TONES TRANSMITTED AND RECEIVED IN THE KIT OF OPTICAL FIBER

\begin{tabular}{|l|l|l|l|l|}
\hline Parameters & Input signals & $\begin{array}{l}\text { Output signals } \\
\text { Output signal when the fiber was } \\
\text { subjected to slight deformations }\end{array}$ \\
\hline $\begin{array}{l}\text { Parameters of } \\
\text { the input signal } \\
\begin{array}{l}\text { m }=210 \mathrm{mVpp} \\
\text { fm=2KHz } \\
\text { length to the } \\
\text { fiber optic: } 50 \mathrm{~cm}\end{array}\end{array}$
\end{tabular}

TABLE 2

SIGNALS MODULATED TRANSMITTED AND RECEIVED IN THE KIT OF OPTICAL FIBER

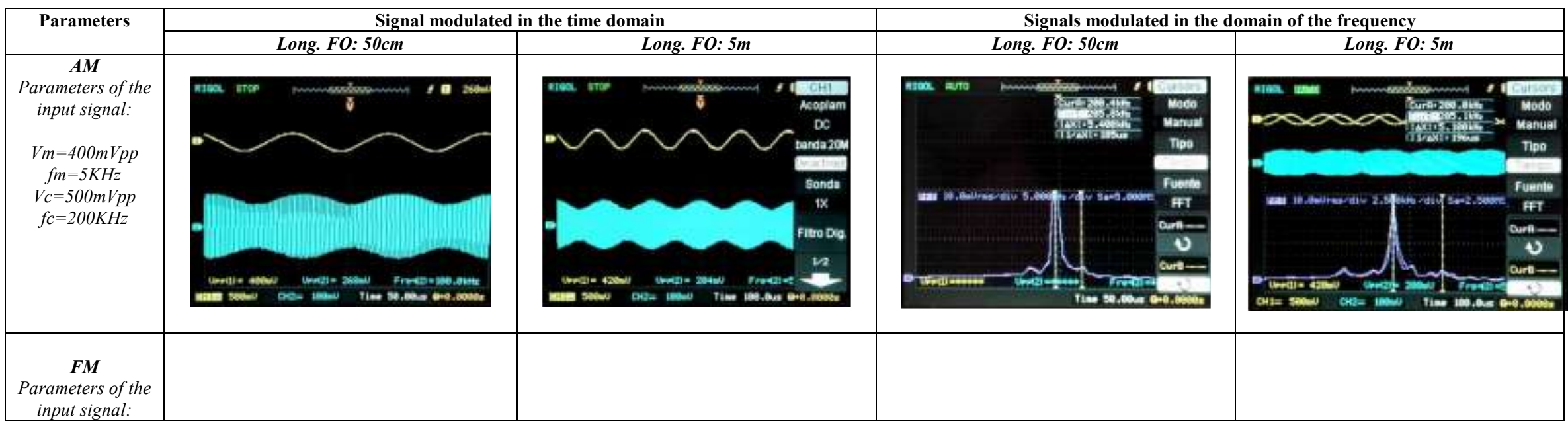

16 $^{\text {th }}$ LACCEI International Multi-Conference for Engineering, Education, and Technology: "Innovation in Education and Inclusion", 19-21 July 2018, Lima, Peru. 


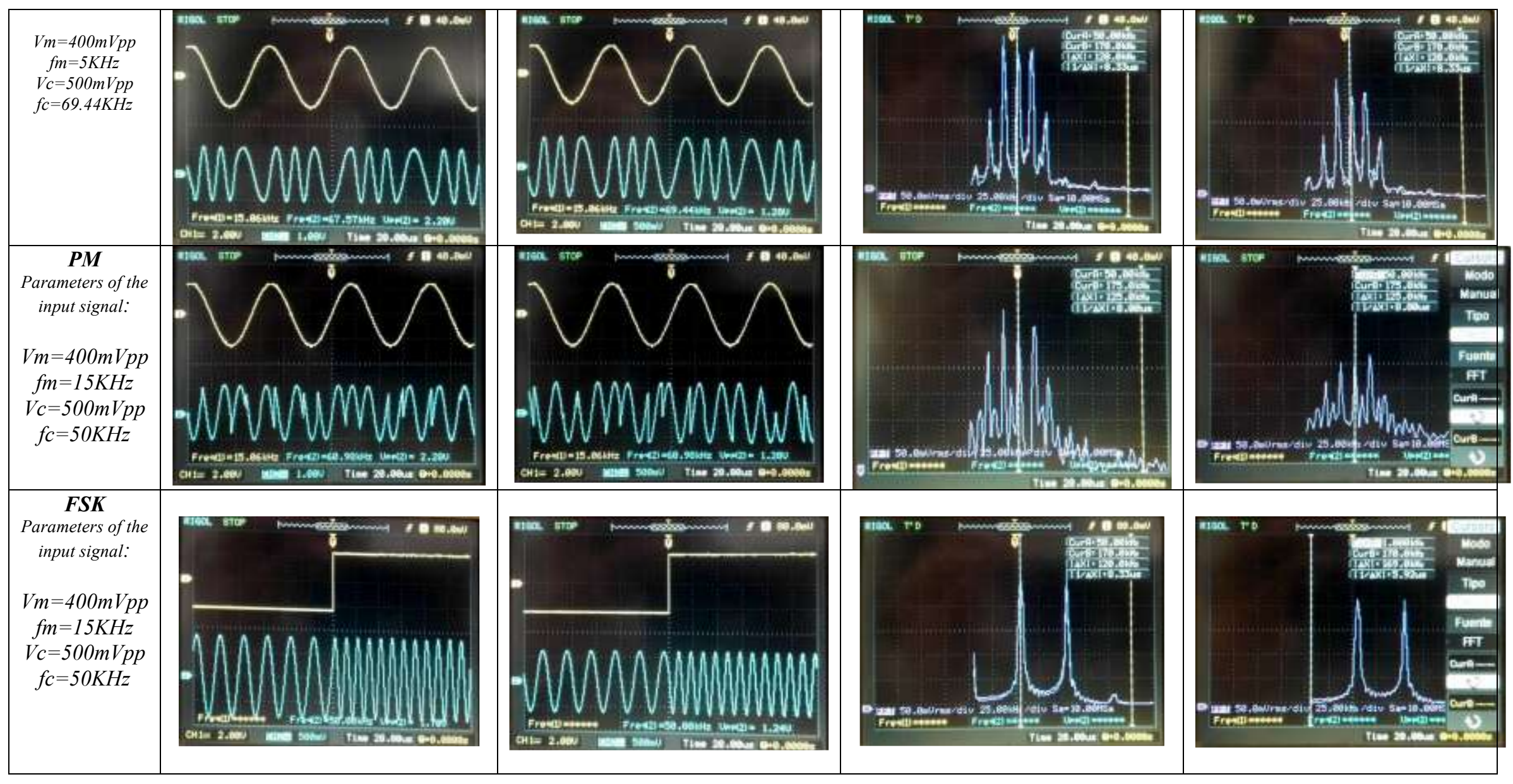

16 $^{\text {th }}$ LACCEI International Multi-Conference for Engineering, Education, and Technology: "Innovation in Education and Inclusion”, 19-21 July 2018, Lima, Peru. 


\section{ANALYSIS OF RESULTS}

In the table 1 is evident that subject to the fiber optic to the different tensions and curvature, change the signal received in the amplitude with respect to the signal transmitted: is submitted attenuation for reflection front of the effort. The tension or curvature of the fiber optic cause that the light that go throught the core was reflected and refract; however, the lost is reversible when the creases disappear: this principle is used in order to, depending to the stress that the fiber is subject, can be evaluated the impact over them and affirm when present an overload.

In the table 3 , can be infer that the transmission of the modulate signal (happen for the type AM, FM and PM analogic modulation-, like for FSK -digital modulation) throught to the panel of DL 2570 to the fiber optic (to length of $5 \mathrm{~m}$ ) present strength loss respect to the transmission of the same signal for fiber optic with the length of $50 \mathrm{~cm}$. the modulation with using the phase PM present the most attenuation in the output signal with respect to the input signal after to the was transmitted then that the signal is transmitted; this is approximately of $63 \%$ for an length of $5 \mathrm{~m}$ of fiber optic, and depend of the frequency of the carrier wave.

$$
\text { TABLE } 3
$$

COMPARISON OF THE PARAMETERS OF AMPLITUD AND FREQUENCY OF THE TRANSMITTED SIGNS VERSUS THE SIGNS RECEIVED FOR THREE TYPES OF ANALOGICAL MODULATION AND DIGITAL

\begin{tabular}{|c|c|c|c|c|c|}
\hline \multirow[b]{2}{*}{ Modulation } & \multirow{2}{*}{$\begin{array}{l}\text { Long. } \\
\mathrm{FO}\end{array}$} & \multicolumn{2}{|c|}{ Input measures } & \multicolumn{2}{|c|}{ Output measures } \\
\hline & & $\begin{array}{c}F \\
(K H z) \\
\end{array}$ & $\begin{array}{c}\text { Amplitude } \\
\text { (Vpp) }\end{array}$ & $\begin{array}{c}F \\
(K H z)\end{array}$ & $\begin{array}{c}\text { Amplitude } \\
\text { (Vpp) }\end{array}$ \\
\hline \multirow{2}{*}{$\mathrm{AM}$} & $50 \mathrm{~cm}$ & 200 & 0.472 & 200 & 0.472 \\
\hline & $5 \mathrm{~m}$ & 200 & 0.472 & 200 & 0.304 \\
\hline \multirow{2}{*}{ FM } & $50 \mathrm{~cm}$ & 69.44 & 0.422 & 67.55 & 0.422 \\
\hline & $5 \mathrm{~m}$ & 69.44 & 0.422 & 69.44 & 0.280 \\
\hline \multirow{2}{*}{$\mathrm{PM}$} & $50 \mathrm{~cm}$ & 50 & 1.24 & 60.98 & 1.24 \\
\hline & $5 \mathrm{~m}$ & 50 & 1.24 & 60.98 & 0.78 \\
\hline \multirow{2}{*}{ FSK } & $50 \mathrm{~cm}$ & 50 & 0.448 & 50 & 0.407 \\
\hline & $5 \mathrm{~m}$ & 50 & 0.448 & 50 & 0.245 \\
\hline
\end{tabular}

The decrease in the amplitude of the modulate signal was as expected because to the quadratic relation between the distance with the power. As regards to the susceptibility of the modulate signal to the noise was see that any type of modulate signal was contaminated with noise due to the type of energy (signal of light) resist any electromagnetic interference.

Also, can be seen that the frequency varies only for some types of modulation like FM and PM. Is logic thought that this type of modulation modifies the frequency and the wave's phase, since the message is going to be codified in these parameters of the carrier wave.
In the received signals isn't evidence distortion of the modulate wave, due to the transmission was for the modulate signal of narrow band. This phenomena's is inversely proportional to the bandwidth and the channel's linearity.

As regards to the simulation, the figures 4 and 6 show the effects of the charge distributed have over the fiber optic. In the figure 4 is evident, throught of colors, the effort to that this exposed the cable of fiber; the zone of color blue is that the fewer efforts, and the zone of color red is that the major effort.

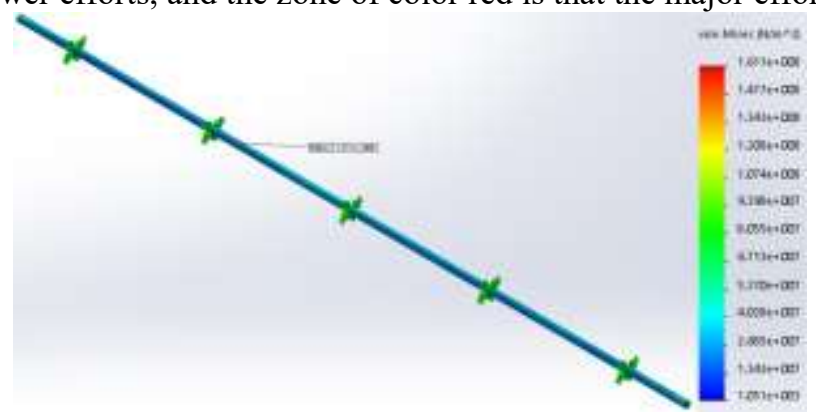

Fig. 4. Distribution of efforts semi-axis of 3 tons (isometric view).

The maximum efforts were near to the $0.16 \mathrm{Mpa}$, and is presented over the core, in a zone near to the limit with the covering. In consequently, the covering has been the material less affected.

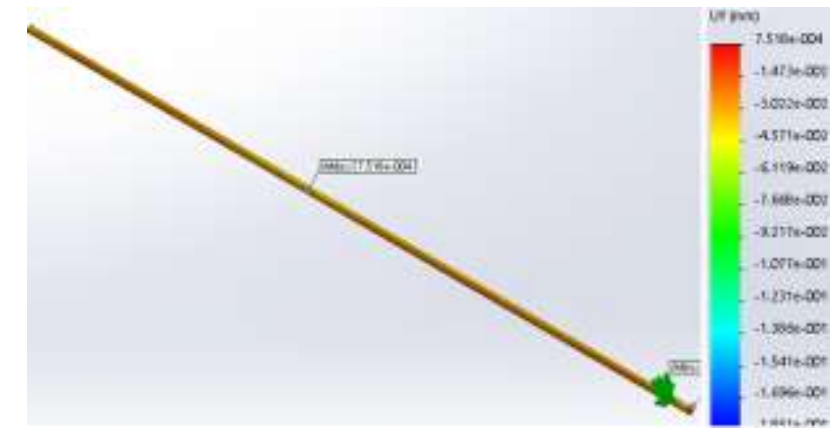

Fig. 5. Displacement with regard to the vertical axis $Y$, semi-axis of 3 tons

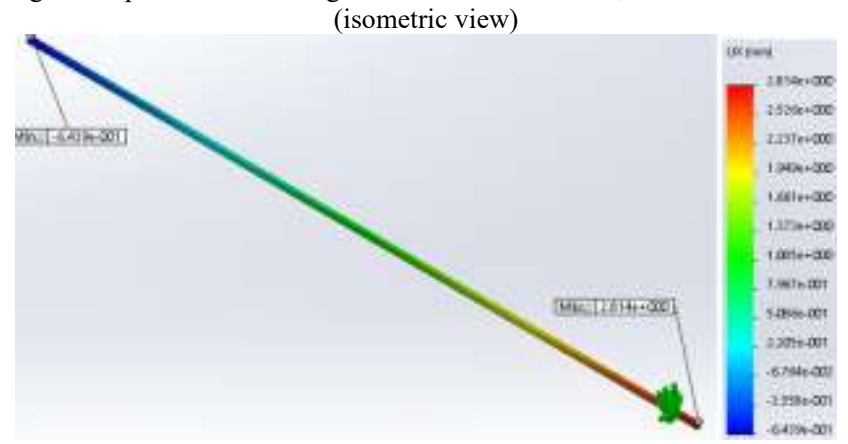

Fig. 6. Displacement with regard to the horizontal axis $\mathrm{X}$, semi-axis of 3 tons (isometric view)

The transversal's displacements maximums that is presented in the fiber are near to the $53.14 \mu \mathrm{m}$ this deformation is proportional to the distance at the application point to the effort, for that reason the zone that it is situated in the bottom will be the most affected, the longitudinal displacements

16 $^{\text {th }}$ LACCEI International Multi-Conference for Engineering, Education, and Technology: "Innovation in Education and Inclusion", 19-21 July 2018, Lima, Peru. 
maximums are of $2.81 \mu \mathrm{m}$ situated in the ends of the cable of fiber.

\section{CONCLUSIONS}

In order to get the theoretical model will be based on the understanding of the physical phenomenon of overload on the pavement. A prototype will be built at scale (physical model as close as possible to reality) on which tests and adjustments of nonconformity will be made; later measurements will be taken, these will construct curves and will make regressions to approach the theoretical model sought. This same procedure will be done by simulation; only that instead of transmitting an electromagnetic signal (light) a fluid will be injected as an analogy of light.

The theoretical fiber-based sensor model will initially be designed for static loads corresponding to $\mathrm{C} 2$ vehicles with a maximum gross vehicle weight of 17 Tons, distributed on the simple directional axis and on a simple, non-directional axis. The investigation will continue in process through simulation and theoretical precision of the reflectometry principle, in order to detect vehicular overload.

Based on the experiences carried out in laboratory under controlled conditions, it was possible to conclude the following:

The maximum efforts generated by a $\mathrm{C} 2$ vehicle do not exceed the elasticity limits of the materials that make up the fiber (2410 and $1070 \mathrm{MPa}$ ), so the assembly used to approach the theoretical model of an optical fiber sensor fulfils the necessary criteria of design to withstand extreme load and temperature conditions.

The axial deformations suffered by the fiber are insignificant to consider that they affect its correct working; however, to achieve variation of the output signal concerning to the input in the model, a modification in the assembly that allows to amplify the existing axial deformation must be thought and thus make that the sensor more easily detect the overloads.

When working under the principle of reflectometry it is required to partially interrupt the emission of the signal by altering the physical conditions of a fiber cable. It was observed that when the fiber is submitted to deformations by external forces (tension, compression, bending), the signal that reaches the receiver is attenuated. Taking into account the above, a test mechanism can be made that allows these deformations to be carried out in a simple way and to be able to evaluate the signal attenuations in respect of the forces applied to the fiber.

\section{REFERENCES}

[1] Castellanos, A.P. \& Rojas, J.P. (2014). Espectros de carga vehicular para la zona urbana de Bogotá D.C .Universidad de los Andes. Online. Recuperado el día 8 de marzo de 2017, de https://www.researchgate.net/publication/242614976_Espectros_de_carga _vehicular_para_la_zona_urbana_de_Bogota_DC
[2] Chaube, P., Colpitts, B.G., Jagannathan, D. and Brown, A.W. (2008). Distributed FiberOptic Sensor for Dynamic Strain Measurement. IEEE Sensors Journal, 8(7), 1067-1072 ISSN 1530437X.

[3] Childs, P., Wong, A.C.L., Terry, W. and Peng, G.D. (2008). Measurement of crack formation in concrete using embedded optical fibre sensors and differential strain analysis. Measurement science and technology, 19(6), pp. 065301. ISSN 0957-0233.

[4] Halliday, D. y Resnick, R. (1978). Física. $3^{\text {a }}$ edición, John Wiley \& Sons, México.

[5] Instituto del transporte. (2015). Del control de las cargas en las rutas y de las dimensiones de los camiones. Buenos Aires, Argentina. Online. Recuperado el 9 de abril de 2017, de:

http://www.acadning.org.ar/Institutos/IT\%20ANI\%20N9\%20Control\%20 de\%20 cargas.pdf

[6] Jiménez. R. \& Fabela, M.J. (2014). Diseño y construcción de un prototipo para determinar el peso de vehículos ligeros en movimiento. Instituto Mexicano del transporte. Online. Recuperado el 15 de marzo de 2017, de:

http://www.imt.mx/archivos/Publicaciones/PublicacionTecnica/pt247.pdf

[7] León, R.O. (2000). Sobrecarga en vías. El Tiempo. Online. Recuperado el 6 de abril de 2017, de: http://www.eltiempo.com/archivo/documento/MAM-1292151

[8] Li, Q., Li, G., Wang, g. and Yuanb, L. (2004). CTOD measurement for cracks in concrete by fiber optic sensors. Optics and Lasers in Engineering, 42(4), 377-388. ISSN 0143-8166.

[9] Macea, L.F., Fuentes, L.G., \& Álvarez, A.E. (2013). Evaluación de factores camión de los vehículos comerciales de carga que circulan por la red vial principal colombiana. Online. Recuperado el 20 de febrero de 2017, de:

https://aprendeenlinea.udea.edu.co/revistas/index.php/ingenieria/

[10] Ministerio de Transporte de Colombia. (2004). Resolución $\mathrm{N}^{\circ}$ 004100 de 2004. Online. Recuperado el 3 de marzo de 2017, de:

https://www.mintransporte.gov.co/Documentos/Normatividad/Resolucione

[11] Ministerio de Transporte de Colombia. (2009). Resolución $\mathrm{N}^{\circ}$ 001782 de 2009. Online. Recuperado el 3 de marzo de 2017, de: https://www.mintransporte.gov.co/Documentos/Normatividad/Resol uciones

[12] Ministerio de Transporte de Colombia. (2009). Resolución $\mathrm{N}^{\circ}$ 006427 de 2009. Online. Recuperado el 3 de marzo de 2017, de:

https://www.mintransporte.gov.co/Documentos/Normatividad/Resolucione

[13] Ministerio de Transporte de Colombia. (2005). Resolución $\mathrm{N}^{\circ} 2888$ de 2005. Online. Recuperado el 3 de marzo de 2017, de:

https://www.mintransporte.gov.co/Documentos/Normatividad/Resolucione $\mathrm{s}$

[14] Muñoz Moner, A.F., Carreño, Y. \& Pardo, A.G. (2012). Sistemas de control inteligentes para tráfico vehicular. Universidad Autónoma de Bucaramanga. Online. Recuperado el 12 de mayo del 2017, de: http://www.unipamplona.edu.co/unipamplona/portalIG/home_40/rec ursos/04_v19_24/revista_20/05112012/02.pdf

[15] Rodríguez-Zurita, G. (2013). Apuntes de Interferometría. Óptica Contemporánea ideas fundamentales. Puebla, México.

16 $^{\text {th }}$ LACCEI International Multi-Conference for Engineering, Education, and Technology: "Innovation in Education and Inclusion", 19-21 July 2018, Lima, Peru. 
[16] Rondón, H., Delgadillo, E., \& Vargas, W. (2014). Diseño, construcción y funcionamiento de un prototipo para medir cargas vehiculares en un pavimento flexible. Revista Ingeniería de Construcción, 29(1). Online. Recuperado el 5 de abril de 2017, de: https://doi.org/10.4067/S0718-50732014000100005

[17] Romero Cortés, L. (2012). Reflectometría óptica en el dominio de la frecuencia (OFDR) para la caracterización de componentes y dispositivos ópticos.

[18] Serwey, R.A. et al. (2005). Física moderna, $3^{\mathrm{a}}$ edición, Mc Graw Hill.

[19] Troncoso Rivera, J.R. \& Murillo Feo, A. (2011). Evaluación del espectro de carga y coeficientes de daño en el corredor de la Avenida Boyacá, Bogotá D.C. Trabajo final de maestría para optar por el título de Magister en Ingeniería Geotecnia. Universidad Nacional de Colombia. Online. Recuperado el 20 de abril del 2017, de: http://www.bdigital.unal.edu.co/5337/2/juanricardotroncosorivera.20 11.pdf.

[20] Vélez, F.J. \& Serpa C.M \& Gómez N.D (2010). Medición de micro deformaciones en las losas de hormigón con sensores de fibra Bragg. Ingeniería y Ciencia, 6. Universidad EAFIT. Online. Recuperado el 2 de mayo de 2017, de:

http://www.scielo.org.co/pdf/ince/v6n11/v6n11a02.pdf

[21] Yin, S., Ruffin, P.B. and Yu. F.T.S. (2008). Fiber Optic Sensors, second edition, CRC Press, ISBN 978-1-4200-5365-4.

[22] Yuan, L., Li, Q., Liang, Y., Yang, J. and Liu, Z. (2001). Fiber optic second sensor for measuring the strain inside the concrete specimen, Sensors and Actuators A: Physical, 94(1-2), 25-31. ISSN 09244247.

$1^{\text {th }}$ LACCEI International Multi-Conference for Engineering, Education, and Technology: "Innovation in Education and Inclusion”, 19-21 July 2018, Lima, Peru. 